\title{
O DIREITO SUCESSÓRIO DO EMBRIÃO CONCEBIDO POR FECUNDAÇÃO
}

\author{
HOMÓLOGA POST- MORTEM 1
}

\author{
Bruna Paludo ${ }^{2}$ \\ Luís Gustavo dos Santos ${ }^{3}$ \\ Recebido em: 12 mar. 2019 \\ Aceito em: 05 dez. 2019
}

\begin{abstract}
RESUMO
A reprodução assistida é técnica que se originou na Inglaterra e conquistou o mundo, surgiu para cessar o anseio daqueles indivíduos, que por motivos alheios as suas vontades, não conseguem ter filhos de maneira natural. O direito se mostrou incapaz de acompanhar estes avanços tecnológicos e seus reflexos na sociedade, fato que não poderia ser diferente, ante a velocidade que ocorrem. Assim, a concepção artificial se torna matéria complexa e controvertida em meio aos doutrinadores, deixando as pessoas inseguras juridicamente frente aos diversos questionamentos que podem ocorrer. O presente artigo tem como intento fazer uma reflexão, no âmbito do direito sucessório, sobre a situação jurídica do embrião concebido por fecundação homóloga post-mortem, uma vez que a legislação brasileira se apresenta omissa em relação ao tema, contando apenas com algumas resoluções do Conselho Federal de Medicina, frente a possíveis conflitos que podem ocorrer.
\end{abstract}

Palavras-chave: Direito Sucessório. Reprodução Humana Assistida. Post-mortem. Biodireito.

\section{INHERITANCE LAW OF THE EMBRYO CONCEIVED BY HOMOLOGOUS}

\section{FERTELIZATION POST MORTEM}

\begin{abstract}
Assisted Reproduction is a technique that originated in England and won over the world. It was created to end the yearning of individuals who, for reasons other than personal ones, were not able to have children in a natural fashion. The law proved itself to be incapable of following these technological advancements and their reflexes in society, a fact that could not be different, due to the speed in which they happen. Therefore, artificial insemination becomes a topic of complexity and controversy among scholars, leaving people legally insecure in the face of the various questions that may arise. The intent of this article is to reflect about the legal status of the embryo conceived by homologous post-mortem fertilization, since the Brazilian legislation stands silent in regards to the subject, counting only with few resolutions from the Federal Medicine Council, faced with possible conflicts that may occur.
\end{abstract}

\footnotetext{
${ }^{1} \mathrm{O}$ direito sucessório do embrião concebido por fecundação homóloga post-mortem.

2 Bruna Paludo. Advogada. Graduada em Direito pela Universidade do Vale do Itajaí-UNIVALI. E-mail: brunapaludo_@hotmail.com. Telefone:(047) 997142470

${ }^{3}$ Luís Gustavo dos Santos. Advogado. Mestre em Ciência Jurídica pela Universidade do Vale do Itajaí - UNIVALI. Professor do Curso de Direito Civil da UNIVALI; Escola do Ministério Público de Santa Catarina e da Escola Superior da Magistratura do Estado de Santa Catarina; Coordenador do Curso de Pós Graduação em Direito Civil Avançado e do Curso de Pós Graduação em Direito Civil e Processo Civil, ambos da UNIVALI; proprietário da empresa Guto Concursos - Curso de Preparação para Carreira Jurídica. E-mail: luisgustavo@univali.br
} 
Keywords: Succession Law. Assisted Human Reproduction. Post-mortem. Biodiversity.

\section{INTRODUÇÃO}

O presente artigo pretende evidenciar a falta de regulamentação dos direitos do embrião criopreservado, concebido após a morte de seu genitor, dando ênfase as questões de direito sucessório.

A discussão se torna válida uma vez que as técnicas reprodutivas se tornaram mais utilizadas e acessíveis a população, são indicadas por médicos, em função de tratamentos de saúde que podem desencadear a infertilidade, doenças de caráter progressivo ou simplesmente para adiar a procriação.

A primeira criança concebida pela técnica de fertilização in vitro, nasceu em 1978 na Inglaterra e hoje, após 41 anos, contabilizam-se aproximadamente 6 milhões de pessoas geradas por meio deste método 4 .

Constata-se, que as técnicas de reprodução humana assistida são cada vez mais procuradas e vieram para contribuir positivamente com a qualidade de vida dos indivíduos, que gostariam de ter filhos e por razões alheias a suas vontades o não podiam.

Em contrapartida o direito se mostrou incapaz de acompanhar o desenvolvimento da ciência, pois, mesmo após 35 anos do nascimento da primeira criança concebida por técnicas de reprodução assistida no Brasil, a legislação pouco dispôs sobre, fato que ocasiona a atual insegurança jurídica.

A política jurídica é o caminho para o disciplinamento desta lacuna. A evolução social, as decisões monocráticas, a jurisprudência e a doutrina atuam no sentido de pavimentar o caminho que a posteriori será definido pelo legislador quando da regulamentação legal da matéria.

Diante de um ordenamento jurídico escasso em relação a temática exposta e o avanço das técnicas de reprodução assistida o jurista precisa se posicionar de maneira excepcional diante de situações nunca antes imaginadas, cabendo a ele e a sociedade se manifestarem a respeito desta nova realidade ${ }^{5}$.

Destarte, constata-se a importância deste estudo acadêmico frente as diversas questões pertinentes ao biodireito, e, especificamente a reprodução assistida, que ganhou espaço e popularidade na sociedade, para que assim, posteriormente, o assunto seja alvo de regulamentação na esfera

\footnotetext{
${ }^{4}$ PRIMO, Walquíria Quida Salles Pereira; CORRÊA, Frederico José Silva; BRASILEIRO, Jean Pierre Barguil. Manual Ginecologia da Sociedade Ginecologia e Obstetrícia de Brasília. $2^{\mathrm{a}} \mathrm{ed}$. Brasília: Editora Luan Comunicação, 2007.p. 328.

${ }^{5}$ FERNANDES, Silvia da Cunha. As Técnicas de Reprodução Humana Assistida e a Necessidade de Sua Regulamentação Jurídica. Rio de Janeiro, Renovar: 2005 p. 57.
} 
legislativa.

\title{
REPRODUÇÃO ASSISTIDA: BREVES CONSIDERAÇÕES
}

A fertilidade sempre foi alvo de interesse da humanidade seja consciente ou inconscientemente pelo instinto de perpetuar sua existência.

De modo contrário, pode-se depreender que a infertilidade causa em grande parte dos indivíduos um impacto social e emocional negativo, como explica Luiz Augusto Teixeira Batista

\begin{abstract}
Considerar a infertilidade apenas como um problema que perturba o bem-estar individual e familiar e a inserção social dos casais é atribuir-lhe um caráter reducionista. Muito mais, deverá ser incluída nos atuais conceitos de doença e considerada como um importante problema de saúde pública.
\end{abstract}

Da mesma maneira entende o Conselho Federal de Medicina que na resolução $n$. 2.121/2015 frisou que a infertilidade humana é problema de saúde, com implicações médicas e psicológicas, e confirmou a legitimidade do anseio de superá-la7 ${ }^{7}$.

Assim, as técnicas de reprodução assistida surgiram com intuito auxiliar os indivíduos que desejam ter filhos, facilitado o processo de concepção.

Marilena C. D. V Corrêa e Maria Andrea Loyola ${ }^{8}$ definem como:

O conjunto de técnicas, tecnologias, equipamentos, procedimentos médicos e biomédicos para a fertilização do embrião in vitro recebe denominações variadas, tais como "reprodução assistida" (RA), "reprodução humana assistida" (RHA), ou ainda "técnicas de reprodução assistida" (TRA), que, na prática, se equivalem.

São processos complexos, que envolvem a manipulação extracorporal de oócitos e espermatozoides ou de embriões, com objetivo facilitar a resolução de problemas relacionados à procriação, desde que tenham chance real de sucesso e que outros tipos de tratamento tenham sido contraindicados ou ineficazes 9 .

Desde seu surgimento foi ampliada a gama de técnicas de reprodução assistida, sendo as principais: Fertilização In Vitro (FIV), Injeção Intracitoplasmática de Espermatozoides (ICIS) e a

\footnotetext{
${ }^{6}$ Cook RJ, Dickens BM. Reducing stigma in reproductive health. Int J Gynaecol Obstet. 2014;125(1):89-92. citado por BATISTA, Luiz Augusto Teixeira; BRETONESA, Wagner Henrique Daibert; e ALMEIDA, Rogério José de. $O$ impacto da infertilidade: narrativas de mulheres com sucessivas negativas pelo tratamento de reprodução assistida. Sociedade Brasileira de Reprodução Humana. Elsevier Editora Ltda: 2016. p. 122.

${ }^{7}$ BRASIL. CONSELHO FEDERAL DE MEDICINA. Resolução n. 2.121/2015. Publicada no D.O.U. de 24 de setembro de 2015, Seção I, p. 117.

${ }^{8}$ CORREAA, Marilena C. D. V; LOYOLA, Maria Andrea. Tecnologias de reprodução assistida no Brasil: opções para ampliar o acesso. Physis Revista de Saúde Coletiva, Rio de Janeiro: 2015. p. 754. Disponível em: $<$ http://www.scielo.br/pdf/physis/v25n3/0103-7331-physis-25-03-00753.pdf>.

${ }^{9}$ PRIMO, Walquíria Quida Salles Pereira; CORRÊA, Frederico José Silva; BRASILEIRO, Jean Pierre Barguil. Manual Ginecologia da Sociedade Ginecologia e Obstetrícia de Brasília. 2a ed. Brasília: Editora Luan Comunicação, 2007.p. 328.
} 
Transferência de Embrião Congelado (TEC).

São consideradas TRA: fertilização in vitro (FIV) e transferência de embriões, transferência intrafalopiana de gametas, transferência intrafalopiana de zigoto, transferência tubária de embriões, criopreservação de gametas e embriões, doação de oócitos ou de embriões, e a gestação de substituição (doação temporária do útero). Não está contemplada pela terminologia a inseminação assistida ou artificial em qualquer modalidade ${ }^{10}$.

Estes métodos ainda se subdividem em: homólogos e heterólogos. No homólogo os espermatozoides introduzidos pertencem ao marido ou companheiro da mulher, o líquido seminal é injetado pelo profissional da medicina no período de ovulação. No heterólogo, o sêmen não pertence ao marido ou companheiro da mulher, normalmente o esperma se encontra num banco de sêmen, cujo doador é totalmente anônimo ${ }^{11}$.

\section{A Reprodução Assistida no Ordenamento Jurídico Brasileiro}

O Brasil não conta com uma legislação específica para atender aos casos de Reprodução Humana Assistida, apesar da sua prática ter começado no país em 1984, no estado do Paraná .

Já tramitaram no Congresso Nacional diversos projetos de lei visando regulamentar a questão, mas nenhum deles teve êxito. Destacam-se, a título desta pesquisa, o PL n. 7.701/2010 que dispõe sobre a utilização post-mortem do sêmen do marido ou companheiro; o PL n. 4.892/2012 que objetiva instituir um estatuto da reprodução humana assistida, afim de regulamentar a aplicação, utilização e efeitos das técnicas de reprodução assistida no âmbito das relações civis sociais; e o PL n. 9.403/2017, que visa estabelecer o direito à sucessão do filho gerado por meio de inseminação artificial após a morte do autor da herança . Deve-se ressaltar ainda que os projetos citados estão apensados ao PL n. 1.184/2003 que aguarda parecer do relator na Comissão de Constituição e Justiça e de Cidadania (CCJC) .

Por conseguinte, utiliza-se, genericamente, a Lei de Biossegurança (n. 11.105/05), que indica conceitos, normas e mecanismos de fiscalização para organismos geneticamente modificados e seus derivados.

Art. 1o Esta Lei estabelece normas de segurança e mecanismos de fiscalização sobre a construção, o cultivo, a produção, a manipulação, o transporte, a transferência, a importação, a exportação, o armazenamento, a pesquisa, a comercialização, o consumo, a liberação no meio ambiente e o descarte de organismos geneticamente modificados - OGM e seus derivados, tendo como diretrizes o estímulo ao avanço

\footnotetext{
${ }^{10}$ PRIMO, Walquíria Quida Salles Pereira; CORRÊA, Frederico José Silva; BRASILEIRO, Jean Pierre Barguil. Manual Ginecologia da Sociedade Ginecologia e Obstetrícia de Brasília. 2aed. Brasília: Editora Luan Comunicação, 2007.p. 328.

${ }^{11}$ NASCIMENTO, Rosane Bezerra do; MATOS Ilzver de Oliveira; LIMA, Kellen Josephine Muniz de. Utilização das Técnicas de Reprodução Assistida pelas Pessoas Trans: Uma Abordagem Jurídica. Disponível em: $<$ http://www.uneb.br/enlacandosexualidades/files/2015/07/COMUNICA\%C3\%87\%C3\%83OORALROSANEN ASCIMENTO2.pdf >
} 
científico na área de biossegurança e biotecnologia, a proteção à vida e à saúde humana, animal e vegetal, e a observância do princípio da precaução para a proteção do meio ambiente ${ }^{12}$.

A inovação normativa desta lei se deve principalmente ao seu artigo $5^{\circ}$, que regulamentou a possibilidade do uso das células tronco provenientes de embriões excedentários (produzidos in vitro), para fins terapêuticos e de pesquisa, desde que:

I - Sejam embriões inviáveis; ou

II - Sejam embriões congelados há 3 (três) anos ou mais, na data da publicação desta Lei, ou que, já congelados na data da publicação desta Lei, depois de completarem 3 (três) anos, contados a partir da data de congelamento ${ }^{13}$.

Salienta-se que em qualquer das hipóteses se faz indispensável o consentimento dos genitores e se veda a comercialização do material biológico.

O referido artigo, em sua totalidade, foi alvo de Ação Direta de Inconstitucionalidade (ADI n. 3.510), proposta pelo Procurador Geral da República, que entendeu que o uso de células tronco para fins de pesquisa ou terapia feria princípios e normas constitucionais básicas, como por exemplo: o caráter fraternal da $\mathrm{CRFB} / 88$ e o direito à vida (art.5\%, caput, $\mathrm{CRFB} / 88$ ).

Em contrapartida, no ano de 2008, o Supremo Tribunal Federal ${ }^{14}$, decidiu, por maioria dos votos, pela total improcedência da ação e consequentemente pela constitucionalidade das pesquisas e terapias realizadas com células tronco embrionárias, nos moldes da lei:

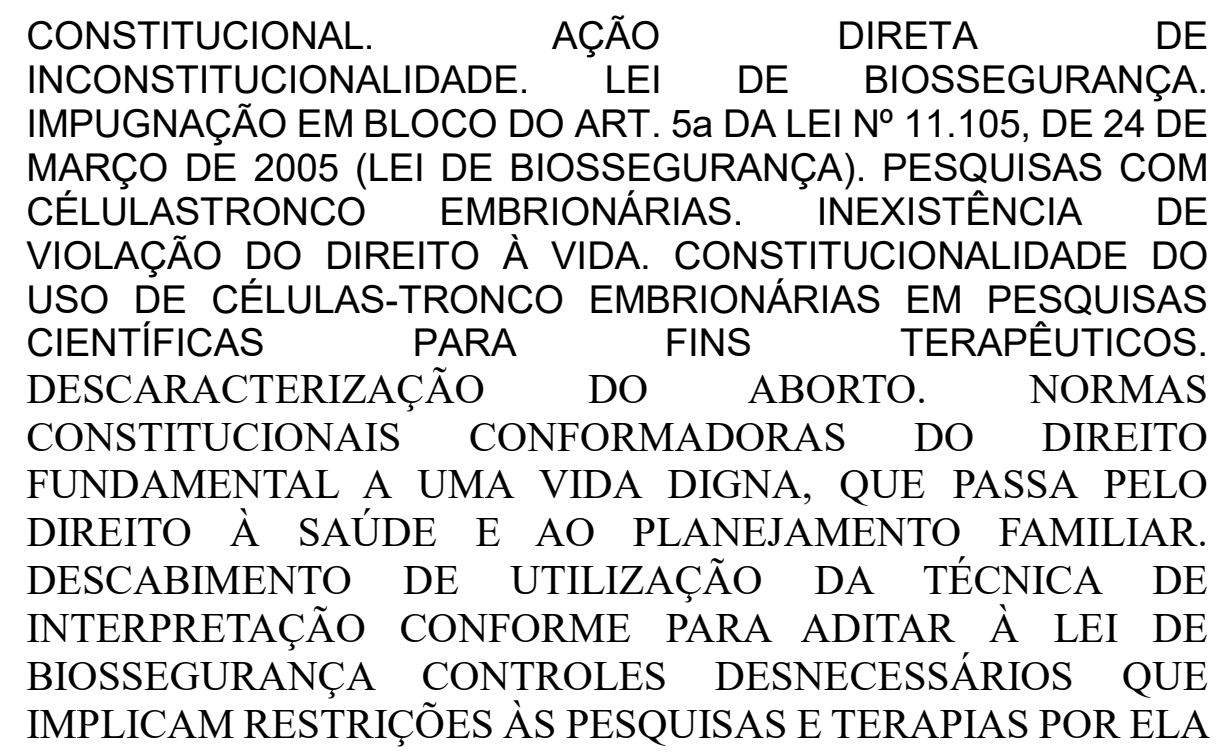

\footnotetext{
${ }^{12}$ BRASIL. Lei n.11.105 de 24 de março de 2005.Lei de Biossegurança. Estabelece normas de segurança e mecanismos de fiscalização de atividades que envolvam organismos geneticamente modificados, seus derivados e dá outras providências. BRASÍLIA, DF. Mar.2005. Disponível em:< http://www.planalto.gov.br/ccivil_03/_Ato2004-2006/2005/Lei/L11105.htm>. Acesso em: 05.fev.2019.

${ }^{13}$ Ibidem, art. $5^{\circ}$.

${ }^{14}$ STF. AÇÃO DIRETA DE INCOSTITUCIONALIDADE. N.3.510, DF. Relator Ministro Aires Britto. 29/05/2008. Disponível em: <http://redir.stf.jus.br/paginadorpub/paginador.jsp?docTP=AC\&docID=611723>. Acesso em: 05.fev.2019.
} 


\section{VISADAS. IMPROCEDÊNCIA TOTAL DA AÇÃO.}

Outro dispositivo que também faz menção a reprodução assistida está previsto no Código Civil $^{15}$, capítulo de Filiação:

Art. 1.597. Presumem-se concebidos na constância do casamento os filhos:

I - Nascidos cento e oitenta dias, pelo menos, depois de estabelecida a convivência conjugal;

II - Nascidos nos trezentos dias subsequentes à dissolução da sociedade conjugal, por morte, separação judicial, nulidade e anulação do casamento;

III - Havidos por fecundação artificial homóloga, mesmo que falecido o marido;

IV - Havidos, a qualquer tempo, quando se tratar de embriões excedentários, decorrentes de concepção artificial homóloga;

V - havidos por inseminação artificial heteróloga, desde que tenha prévia autorização do marido.

Artigo que, em suma, determina a presunção de paternidade daqueles que foram concebidos postumamente por inseminação artificial homóloga.

Porém, o Código Civil não contempla a matéria de maneira completa, o legislador limitouse a estabelecer apenas reconhecimento legal da paternidade nos casos de concepção artificial, fato compreensível, em virtude da complexidade e amplitude do tema, que merece tratamento legal em lei própria $^{16}$.

Apesar de não terem força de lei, devem ser observadas também as deliberações do Conselho Federal Medicina. Recentemente foi editada a Resolução n. 2.168/2017 que estabeleceu parâmetros éticos para utilização das técnicas artificiais de reprodução, proporcionando mais segurança para os profissionais, que exercem o método, e para os pacientes em suas vulnerabilidades ${ }^{17}$.

Foi criada com intuito de modificar e atualizar dispositivos anteriores (Resolução CFM n. 2.121/2015), e seus principais pontos modificados foram: a) a possibilidade de planejar o aumento da família levando em conta projetos de trabalho ou estudo; b) o acesso da técnica de reprodução assistida aos pacientes que por conta de tratamentos ou doenças poderão ter um quadro de infertilidade e; c) a ampliação do número de parentes que podem ceder o útero para uma gravidez ${ }^{18}$.

15 BRASIL. Lei n. $\mathbf{1 0 . 4 0 6}$ de $\mathbf{1 0}$ de janeiro de 2002. Código Civil. Disponível em: < http://www.planalto.gov.br/ccivil_03/leis/L3071.htm>. Acesso em: 25.fev.2019.

${ }^{16}$ SILVA, Regina Beatriz Tavares da. coord. Código Civil Comentado. 8. ed. São Paulo: Saraiva, 2012. n.p.

17 CONSELHO FEDERAL DE MEDICINA. Resolução n. 2.168. Adota normas éticas para a utilização das técnicas de reprodução $\quad$ assistida. em:<https://sistemas.cfm.org.br/normas/visualizar/resolucoes/BR/2017/2168>. Acesso em:05.fev.2019.

$18 \quad$ Informação disponível em: $<$ https://portal.cfm.org.br/index.php?option=com_content\&view=article\&id=27280:2017-11-10-12-38$28 \&$ catid $=3>$. Acesso em: 05.fev.2019. 


\title{
A REPRODUÇÃO ASSISTIDA POST-MORTEM NO ORDENAMENTO JURÍDICO
}

\section{BRASILEIRO}

A Reprodução Humana Assistida Post-mortem consiste em implantar embrião ou material genético que estava criopreservado, após a morte de um dos genitores

\begin{abstract}
O desenvolvimento das técnicas de criopreservação permitiu que se aventasse a possibilidade do uso de gametas e embriões para concepção após a morte de um dos membros do casal, levantando questionamentos éticos e morais, e preocupações quanto ao desenvolvimento psicossocial das crianças dessa forma concebidas. É consensual entre os especialistas que o consentimento para TRA póstuma deve ser documentado por ambas as partes, para minimizar as consequências de sua realização e evitar judicialização do tratamento ${ }^{19}$.
\end{abstract}

No ordenamento jurídico brasileiro não há legislação proibitiva nem permissiva no que tange a reprodução assistida post-mortem, há uma omissão por parte do legislador.

Já houve a propositura de um Projeto de Lei, n. 7.701/2010, de autoria de Maria Dalva de Souza Figueiredo, que propunha que, o sêmen criopreservado, só poderia ser utilizado no post-mortem, com autorização expressa do companheiro em vida, pela viúva ou ex-companheira, em até trezentos dias após o óbito, tal proposta foi apensada ao PL n. 1.184/2003 e ainda aguarda parecer ${ }^{20}$.

Atualmente, diante da ausência de legislação específica o CFM em sua Resolução n. 2.168/2017, já citada anteriormente, estabeleceu algumas normas e princípios básicos para a utilização das técnicas de concepção artificial, mas no que diz respeito, particularmente, a reprodução assistida post-mortem deliberou apenas que a mesma seria permitida desde que autorizada previamente pelo falecido ${ }^{21}$.

Assim, perante tantas omissões legislativas é manifestamente relevante a discussão sobre a matéria em tela, e o impacto que ela detém sobre a sociedade e as relações que a permeiam, sejam estas, jurídicas, sociológicas ou filosóficas.

\section{REFLEXOS JURÍDICOS DA ISEMINAÇÃO POST-MORTEM NO DIREITO}

\section{SUCESSÓRIO}

Diante das lacunas legislativas apresentadas, constituem-se também diversos

\footnotetext{
${ }^{19}$ PRIMO, Walquíria Quida Salles Pereira; CORRÊA, Frederico José Silva; BRASILEIRO, Jean Pierre Barguil. Manual Ginecologia da Sociedade Ginecologia e Obstetrícia de Brasília. 2a ed. Brasília: Editora Luan Comunicação, 2007.p. 20.

${ }^{20}$ ROCHA, Maria Elizabeth Guimarãe Teixeira. Bioética em Face da Legislação Brasileira e do Mercosul. p.140. Disponível em: <http://www.ipea.gov.br/portal/images/stories/PDFs/livros/livros/bioetica-texto-paradebate-3.pdf $>$. Acesso em: 25.fev.2019

${ }^{21}$ Conselho Federal de Medicina. Resolução n. 2.168/2017. Adota normas éticas para utilização das técnicas de reprodução assistida. Disponivel em: <https://sistemas.cfm.org.br/normas/visualizar/resolucoes/BR/2017/2168>. Acesso em: 25.fev.2019.
} 
questionamentos legais, dentre eles se o embrião concebido pela fecundação artificial post-mortem tem capacidade para suceder ou não.

Entende-se, de maneira ampla, que "suceder" é tomar o lugar de outrem no campo dos fenômenos jurídicos, substituindo o titular de um direito"²2.

Esta sucessão pode ocorrer inter vivos, quando integra em sua maioria apenas direitos das obrigações (compra, venda, doação, ...) ou causa mortis, quando decorre da morte de um indivíduo, esta também pode ser chamada de sucessão hereditária qual transmite direitos e obrigações de uma pessoa morta a outra pessoa viva.

A sucessão causa mortis, objeto da presente pesquisa, pode ser ainda classificada como legitima, que decorre em virtude de lei ou testamentária, quando o próprio titular do patrimônio declara sua vontade, estabelecendo os termos em que se dará a sucessão.

Uma das problemáticas atinentes ao objeto deste estudo diz respeito a natureza jurídica do embrião criopreservado, no sentido de ser considerado ou não um nascituro.

Para responder este questionamento deve-se partir do princípio e fazer um breve apanhado sobre as principais teorias do início da personalidade civil. Existem diversas teses mas dentre elas destacam-se basicamente: a) Teoria Natalista, adotada pelo Código Civil brasileiro, que determina que a capacidade civil ocorre com o nascimento com vida mas não explica o porquê de se assegurar o direito do nascituro; b) Teoria da Personalidade condicional, que é essencialmente Natalista, assegura a personalidade a contar da concepção mas desde que o nascimento ocorra com vida e; c) Teoria Concepcionista, qual adota-se nesta pesquisa, garante os direitos de personalidade desde a concepção (junção do espermatozoide com o oócito). ${ }^{23}$

Porém, Silmara J.A.Chinellato ${ }^{24}$, adepta da corrente concepcionista, explica:

Apenas certos efeitos de certos direitos, isto é, os direitos patrimoniais materiais como a herança e a doação, dependem do nascimento com vida

$$
[\ldots .]
$$

Porém a posse dos bens herdados ou doados ao nascituro pode ser exercida, por seu representante legal, desde a concepção, legitimando-o a perceber rendas e frutos, na qualidade de titular de direito subordinado à condição resolutiva.

Neste momento, adentra-se ao tema da capacidade sucessória e sobre esta o Código Civil ${ }^{25}$

\footnotetext{
${ }^{22}$ VENOSA, Silvio de Salvo. Direito Civil: Direito das Sucessões. $7^{\circ}$ vol. 13ª edição. São Paulo. Atlas: 2013. n.p.

${ }^{23}$ CHINELLATO, Silmara Juny de Abreu. A pessoa natural na quarta era de direitos: O nascituro e o embrião pré-implantado. p.90-97.Disponível em: <http://www.idclb.com.br/revistas/32/revista32\%20(7).pdf> Acesso em: 05.fev.2019.

${ }^{24}$ CHINELLATO, Silmara Juny de Abreu. A pessoa natural na quarta era de direitos: O nascituro e o embrião pré-implantado. p.98.Disponível em: <http://www.idclb.com.br/revistas/32/revista32\%20(7).pdf> Acesso em: 05.fev.2019.

25 BRASIL. Lei n. 10.406, de 10 de maio janeiro de 2002. Institui o Código Civil. Disponível em: < http://www.planalto.gov.br/ccivil_03/LEIS/2002/L10406.htm>. Acesso em: 25.fev.2019.
} 
estabelece em seu art. 1.798 que: "Legitimam-se a suceder as pessoas nascidas ou já concebidas no momento da abertura da sucessão".

Frente a este artigo alguns autores se posicionam contrariamente a ideia de que os embriões fecundados post-mortem tenham direito a herança, pois, compreendem que estes não se enquadram como nascituros ou como concebidos e, portanto, não possuem capacidade civil.

Paulo Lôbo ${ }^{26}$ considera que:

A concepção de que trata a lei é que se dá no ventre materno, com implantação exitosa, ainda que tenha origem em inseminação artificial ou in vitro. Para fins de sucessão, não se considera fecundação in vitro, cujo embrião não tenha sido implantado no útero materno, pois não se qualifica como nascituro.

$[\ldots]$

O Código Civil faz distinção entre concepção e fecundação ou inseminação, dai se concluindo que há concepção a partir da nidação (fixação do óvulo fecundado à parede do útero), não fecundação, ou da inseminação, ou da técnica de reprodução assistida, como alguns preferem denominar esses eventos. Enquanto não ocorre a nidação, o embrião que foi fecundado in vitro (fora do organismo feminino) não é considerado concebido para fins de sucessão legítima.

Corrobora com este entendimento Eduardo de Oliveira Leite ${ }^{27}$ que doutrina:

[...] quanto à criança concebida por inseminação post mortem, ou seja, criança gerada depois do falecimento dos progenitores biológicos, pela utilização de sêmen congelado, é situação anômala, quer no plano do estabelecimento da filiação, quer no do direito das sucessões. Nesta hipótese a criança não herdará de seu pai porque não estava concebida no momento da abertura da sucessão".

Para complementar Carlos Roberto Gonçalves ${ }^{28}$, ensina que:

Em princípio não se pode falar em direitos sucessórios daquele que foi concebido por inseminação artificial post mortem, uma vez que, a transmissão da herança se dá em consequência da morte (CC, art. 1784) e dela participam as " pessoas nascidas ou já concebidas no momento da abertura da sucessão” (art. 1798).

No entanto, em sua doutrina, o mesmo confirma que a questão é tormentosa, visto que não há como afastar a interpretação do art.1.597 do $\mathrm{CC}$ e o art. 227 , $\S 6^{\circ}$, da $\mathrm{CRFB} / 88$, os quais consagram a absoluta igualdade de direitos entre os filhos, da interpretação analógica de que todos por consequência, independente se forem fecundados post-mortem ou em vida, devem ter seus direitos sucessórios assegurados.

A luz deste pensamento, de igualdade de direitos, apresenta-se o posicionamento dos autores que defendem, integralmente, o direito a suceder do embrião criopreservado e fecundado postumamente, teoria qual este trabalho também filia-se em função dos preceitos pelos quais é regido

\footnotetext{
${ }^{26}$ LOBO, Paulo. Direito Civil: Sucessões. $3^{\mathrm{a}} \mathrm{ed}$. São Paulo. Saraiva, 2016. p.107.

${ }^{27}$ LEITE, Eduardo de Oliveira. Comentários ao Novo Código Civil, volume XXI: do direito das sucessões, $2^{\mathrm{a}}$ ed. Rio de Janeiro: Forense, 2003. p.110

${ }^{28}$ GONÇALVES, Carlos Roberto. Direito civil brasileiro, volume 7: direito das sucessões. 11. ed. São Paulo: Saraiva, 2017.
} 
o ordenamento jurídico brasileiro, conforme será explicado a seguir.

Carlos Cavalcanti de Albuquerque Filho ${ }^{29}$ explica:

[...] Na hipótese acima ventilada não se vai discutir se o autor da herança desejou ter o filho, manifestou inequivocamente a sua vontade, o simples fato de a criança existir e uma vez comprovada a relação de parentesco já seria suficiente para fazer inserir, na ordem de vocação hereditária, um herdeiro legítimo, da classe dos descendentes, de primeiro grau, na condição de filho, com direito à sucessão.

Como já mencionado Silmara J.A. Chinellato ${ }^{30}$ também adota este pensamento:

[...] o embrião pré-implantatório poderá herdar como herdeiro legítimo ou testamentário. Como legítimo, se houver coincidência entre a mãe que gera e a que o gesta, depois de um tempo de criopreservação. Como testamentário, se forem diferentes pessoas a doadora do óvulo e a que gesta, como no caso de fertilização heteróloga ou fertilização por doadora.

Estas disposições são amparadas por princípios básicos, como direito a vida (art. $5^{\circ}$, caput, $\mathrm{CFRB} / 88$ ); dignidade da pessoa humana (art. $1^{\circ}$, III, CRFB/88); igualdade (art. $5^{\circ}$, caput, $\mathrm{CRFB} / 88$ ); não discriminação (art.3 $3^{\circ}, \mathrm{IV}, \mathrm{CRFB} / 88$ ); planejamento familiar (art. 226, $\S 7^{\circ}, \mathrm{CRFB} / 88$ ); e a proteção da criança e do adolescente (art. 227, caput, CRFB/88).

Há ainda um terceiro entendimento daqueles que defendem os direitos sucessórios do embrião excedentário apenas por meio do instituto da prole eventual (sucessão testamentária), previsto no art. 1.799 do Código Civil ${ }^{31}$, que dispõe que "Na sucessão testamentária podem ainda ser chamados a suceder: os filhos, ainda não concebidos, de pessoas indicadas pelo testador, desde que vivas estas ao abrir-se a sucessão".

Dimas Messias de Carvalho ${ }^{32}$ explica:

Na hipótese de a mulher utilizar o sêmen do marido já falecido ou embrião excedentário, haverá muita discussão sobre os direitos sucessórios, com reflexos inclusive na legítima.

A regra geral é que possui testamenti factio passiva a pessoa existente, física ou jurídica (art.1.988, II, CC) ou já concebida no momento da morte do testador.

$[\ldots]$

A situação dos embriões excedentários pode ser solucionada se o testador prever essa hipótese no testamento, apesar da discussão que se trava sobre sua situação jurídica, já que não podem ser considerados nascituros, pois não estão em gestação e nem prole

${ }^{29}$ FILHO, Carlos Cavalcanti de Albuquerque. Fecundação Artificial Post-mortem e o Direito Sucessório. Disponível em: <http://www.ibdfam.org.br/_img/congressos/anais/8.pdf>. Acesso em: 05.fev.2019.

${ }^{30}$ CHINELLATO, Silmara Juny de Abreu. A pessoa natural na quarta era de direitos: O nascituro e o embrião pré-implantado. Revista Brasileira de Direito Comparado. Revista Brasileira de Direito Comparado. p.91. Disponível em: <http://www.idclb.com.br/revistas/32/revista32\%20(7).pdf > Acesso em: 05.fev.2019. 31

${ }^{32}$ CARVALHO, Dimas Messias de. ed. Direito das Sucessões: Inventário e Partilha: teoria, jurisprudência e esquemas práticos. Atualizado conforme a Lei 11.441/2007. Belo Horizonte: Del Rey:2007. p.101. 
eventual, pois já foram concebidos. A melhor solução, todavia, é aplicar as regras da prole eventual, na ausência de previsão legal.

José Heleno de $\operatorname{Lima}^{33}$ ensina que a prole eventual "se apresenta apenas na sucessão testamentária, é uma exceção no direito sucessório brasileiro, que tem como regra o princípio da coexistência, ou seja, só tem capacidade para herdar os nascidos ou concebidos à época da abertura da sucessão".

Art. 1.800. No caso do inciso I do artigo antecedente, os bens da herança serão confiados, após a liquidação ou partilha, a curador nomeado pelo juiz.

$\S 1$ 1o Salvo disposição testamentária em contrário, a curatela caberá à pessoa cujo filho o testador esperava ter por herdeiro, e, sucessivamente, às pessoas indicadas no art. 1.775 .

$\S 2^{\circ}$ Os poderes, deveres e responsabilidades do curador, assim nomeado, regem-se pelas disposições concernentes à curatela dos incapazes, no que couber.

§ 3o Nascendo com vida o herdeiro esperado, ser-lhe-á deferida a sucessão, com os frutos e rendimentos relativos à deixa, a partir da morte do testador.

$\S 4^{\circ} \mathrm{Se}$, decorridos dois anos após a abertura da sucessão, não for concebido o herdeiro esperado, os bens reservados, salvo disposição em contrário do testador, caberão aos herdeiros legítimos.

Isto posto, sintetiza-se que no caso de se utilizar analogicamente o instituto da prole eventual para amparar os direitos sucessórios do embrião excedentário, concebido post-mortem, os bens, após a partilha, deverão ser entregues a um curador, que irá os administrar, até no máximo dois anos após a abertura da sucessão, se o testador não dispor de outro modo, e no caso do embrião não for implantado/não houver herdeiro, os bens retornarão ao espólio para que os outros herdeiros os partilhem.

\section{CONCLUSÃO}

Diante do exposto finda-se a presente pesquisa sem exaurir o tema, uma vez que o assunto é de extrema complexidade e não possui regulamentação no Brasil.

A Reprodução Humana Assistida é uma técnica criada em 1978 na Inglaterra, cuja finalidade é facilitar o processo de procriação de indivíduos que por razões alheias as suas vontades não conseguem ter filhos.

Atualmente o método de concepção artificial é bastante solicitado seja, por motivos de saúde, tratamento, indicação médica ou simplesmente para adiar a concepção, assim, por consequência

${ }^{33}$ LIMA, José Heleno de. O tratamento jurídico da prole eventual no Brasil: da inquietação sucessória às indiferenças. Revista Âmbito Jurídico. Disponível em: <http://www.ambitojuridico.com.br/site/?n_link=revista_artigos_leitura\&artigo_id=12152>. Acesso em: 05.fev.2019. 
surgiu a necessidade de se implementar normas específicas sobre o tema no ordenamento jurídico brasileiro.

No que tange a filiação do embrião fecundado post-mortem o assunto já está praticamente pacificado, mas no que concerne os direitos sucessórios do embrião fecundado post-mortem ainda existem inúmeros posicionamentos, que se resumem a três principais: a) os que são totalmente contra os direitos sucessórios daquele fecundado postumamente, os que são integralmente a favor e os que preferem usar, por analogia, o instituto da sucessão testamentária/prole eventual para regulamentar o tema.

O presente trabalho filia-se, com base ao direito a igualdade, ao segundo posicionamento mencionado, uma vez que para se utilizar o material genético post-mortem já é necessária a expressa declaração de vontade do genitor que veio a falecer e como regra geral, de acordo com o Código Civil, há presunção de paternidade na fecundação homóloga post-mortem.

Apesar do embrião concebido in vitro não ser considerado nascituro, pela maioria da doutrina, uma vez que não está implantado no ventre materno a teoria Concepcionista assegura seus direitos e pode-se depreender, que a Lei de Biossegurança também, uma vez que só permite seu uso em pesquisas quando forem inviáveis ou depois de três anos em ambos os casos com a autorização dos genitores.

De qualquer maneira há necessidade de se estabelecer normas e critérios em lei específica, para assim, assegurar os direitos e deveres referentes aos indivíduos envolvidos no processo de reprodução humana assistida.

\section{REFERÊNCIA}

Conselho Federal de Medicina. Resolução n. 2.168/2017. Adota normas éticas para utilização das técnicas de reprodução assistida. Disponivel em: $<$ https://sistemas.cfm.org.br/normas/visualizar/resolucoes/BR/2017/2168>.

BRASIL. CONSELHO FEDERAL DE MEDICINA. Resolução n. 2.121/2015. Publicada no D.O.U. de 24 de setembro de 2015, Seção I.

BRASIL. Lei n. 10.406 de 10 de janeiro de 2002. Código Civil. Disponível em: < http://www.planalto.gov.br/ccivil_03/leis/L3071.htm>. Acesso em: 25.fev.2019.

SILVA, Regina Beatriz Tavares da. coord. Código Civil Comentado. 8. ed. São Paulo: Saraiva, 2012. n.p.

BRASIL. Lei n.11.105 de 24 de março de 2005.Lei de Biossegurança. Estabelece normas de segurança e mecanismos de fiscalização de atividades que envolvam organismos geneticamente modificados, seus derivados e dá outras providências. BRASÍLIA, DF. Mar.2005. Disponível em:< http://www.planalto.gov.br/ccivil_03/_Ato2004-2006/2005/Lei/L11105.htm>. Acesso 
em: 05.fev.2019.

BRASIL. Senado Federal. Projeto de Lei n. 1.184 de junho de 2003. Dispõe sobre Reprodução Assistida. Disponível em: $<$ http://www.camara.gov.br/proposicoesWeb/fichadetramitacao?idProposicao=118275> Acesso em: 01 fev.2019. Texto Original.

CARVALHO, Dimas Messias de. ed. Direito das Sucessões: Inventário e Partilha: teoria, jurisprudência e esquemas práticos. Atualizado conforme a Lei 11.441/2007. Belo Horizonte: Del Rey:2007.

CHINELlATO, Silmara Juny de Abreu. A pessoa natural na quarta era de direitos: 0 nascituro e o embrião pré-implantado. p.90-97.Disponível em: $<$ http://www.idclb.com.br/revistas/32/revista32\%20(7).pdf> Acesso em: 05.fev.2019.

CONSELHO FEDERAL DE MEDICINA. Resolução n. 2.168. Adota normas éticas para a utilização das técnicas de reprodução assistida. Disposto em: $<$ https://sistemas.cfm.org.br/normas/visualizar/resolucoes/BR/2017/2168>. Acesso em:05.fev.2019.

Cook RJ, Dickens BM. Reducing stigma in reproductive health. Int $\mathrm{J}$ Gynaecol Obstet. 2014;125(1):89-92. citado por BATISTA, Luiz Augusto Teixeira; BRETONESA, Wagner Henrique Daibert; e ALMEIDA, Rogério José de. O impacto da infertilidade: narrativas de mulheres com sucessivas negativas pelo tratamento de reprodução assistida. Sociedade Brasileira de Reprodução Humana. Elsevier Editora Ltda: 2016.

CORRÊA, Marilena C. D. V; LOYOLA, Maria Andrea. Tecnologias de reprodução assistida no Brasil: opções para ampliar o acesso. Physis Revista de Saúde Coletiva, Rio de Janeiro: 2015. Disponível em: <http://www.scielo.br/pdf/physis/v25n3/0103-7331-physis-25-0300753.pdf>.

FERNANDES, Silvia da Cunha. As Técnicas de Reprodução Humana Assistida e a Necessidade de Sua Regulamentação Jurídica. Rio de Janeiro, Renovar: 2005.

FILHO, Carlos Cavalcanti de Albuquerque. Fecundação Artificial Post-mortem e o Direito Sucessório. Disponível em: <http://www.ibdfam.org.br/_img/congressos/anais/8.pdf $>$. Acesso em: 05.fev.2019.

LEITE, Eduardo de Oliveira. Comentários ao Novo Código Civil, volume XXI: do direito das sucessões, $2^{\mathrm{a}}$ ed. Rio de Janeiro: Forense, 2003. p.110

GONÇALVES, Carlos Roberto. Direito civil brasileiro, volume 7: direito das sucessões. 11. ed. São Paulo: Saraiva, 2017.

LIMA, José Heleno de. O tratamento jurídico da prole eventual no Brasil: da inquietação sucessória às indiferenças. Revista Âmbito Jurídico. Disponível em: <http://www.ambitojuridico.com.br/site/?n_link=revista_artigos_leitura\&artigo_id=12152

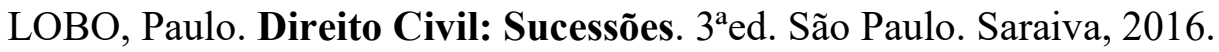

NASCIMENTO, Rosane Bezerra do; MATOS Ilzver de Oliveira; LIMA, Kellen Josephine 
Muniz de. Utilização das Técnicas de Reprodução Assistida pelas Pessoas Trans: Uma Abordagem Jurídica. Disponível em: $<$ http://www.uneb.br/enlacandosexualidades/files/2015/07/COMUNICA\%C3\%87\%C3\%83O ORALROSANENASCIMENTO2.pdf >

PRIMO, Walquíria Quida Salles Pereira; CORREAA, Frederico José Silva; BRASILEIRO, Jean Pierre Barguil. Manual Ginecologia da Sociedade Ginecologia e Obstetrícia de Brasília. $2^{a}$ ed. Brasília: Editora Luan Comunicação, 2007.

ROCHA, Maria Elizabeth Guimarãe Teixeira. Bioética em Face da Legislação Brasileira e do Mercosul. p.140. Disponível em: $<$ http://www.ipea.gov.br/portal/images/stories/PDFs/livros/livros/bioetica-texto-para-debate3.pdf>. Acesso em: 25.fev.2019

SOUZA, Karla Keila Pereira Caetano; ALVES, Oslania de Fátima. As Principais Técnicas de Reprodução Humana Assistida. Revista Acadêmica do Instituto de Ciências da Saúde. v.2, n. 01: Jan-Julho, 2016.

STF. AÇÃO DIRETA DE INCOSTITUCIONALIDADE. N.3.510, DF. Relator Ministro Aires Britto. 29/05/2008. Disponível em: $<$ http://redir.stf.jus.br/paginadorpub/paginador.jsp?docTP=AC\&docID=611723 $>$. Acesso em: 05.fev.2019.

VENOSA, Silvio de Salvo. Direito Civil: Direito das Sucessões. $7^{\circ}$ vol. $13^{a}$ edição. São Paulo. Atlas: 2013. 